\title{
COVID-19 Pandemic and Online Teaching Preparedness of Pakistani Pharmacy Educational Institutions
}

\author{
Hussain, K. ${ }^{1}$, Salman, M. $^{2} \&$ Shehzadi, ${ }^{1}{ }^{1}$
}

We want to write about pharmacy institutions preparedness and response of regulators Higher Education Commission (HEC) and Pharmacy Council of Pakistan (PCP) - to adopt online teaching in lockdown during the COVID19 pandemic. On the very first case report, HEC closed educational institutions for a few weeks, initially declaring this period as summer vacation, but later directed adoption of online teaching without assessing preparedness and considering the ground realities. After media criticism, HEC modified its directive and started tackling the problems of online teaching, including information technology infrastructure development, faculty training, monitoring and internet availability/connectivity.

This paradigm shift - replacing over-the-years practiced conventional teaching - was challenging because of institutional capacity and capability, and the diversely scattered student body. Although, there was an ample time between the emergence of COVID-19 in China and the first case report in Pakistan, neither pharmacy institutions nor regulating authorities predicted the impact of the disease and trained faculty for adopting online teaching (WHO, 2020). However, institutions started online teaching using several different IT approaches, which led to many complaints regarding connectivity and poor lecture content quality. Hence, some universities were directed to stop online teaching and develop necessary infrastructure by May 31, 2020.

\footnotetext{
${ }^{1}$ Punjab University College of Pharmacy, University of the Punjab, Lahore-54000, Pakistan.

${ }^{2}$ Faculty of Pharmacy, The University of Lahore, Lahore, Pakistan.

Corresponding Author: Professor Khalid Hussai

Punjab University College of Pharmacy, University of the Punjab, Lahore-54000, Pakistan.

Email: khussain.pharmacy@pu.edu.pk
}

HEC further proposed a 4-point program to solve connectivity issues, however, PCP failed in providing guidelines to adopt a single mode of online teaching, student evaluation/ promotion criteria and new intake procedure.

It is worth mentioning that pharmacy institutions remained facilitative; providing reading material to students living in remote areas, commiting to take compensatory classes and offering a chance to complete missing courses in future semesters without any tuition fee. The institutions further planned to cover practicalbased courses and attachments/clerkships on resuming academic activities. The institutions may have a further bigger challenge of new intake criteria because entrance qualifying examinations were postponed in the pandemic. Hence, there is a dire need of HEC and PCP guidelines for consistent lecturing, examination procedure and student-intake criteria for all pharmacy institutes to maintain consistency and avoid that reported earlier (Hussain, 2010).

\section{References}

World Health Organization. (2020), https://www.who.int/news-room/detail/27-042020-who-timeline---covid-19. [Accessed 26 May 2020].

Hussain K. (2010) Unstandardized and defective evaluation practices in the examination system in pharmacy institutes of Pakistan. American Journal of Pharmaceutical Education, 74, pp.16c. 